\title{
I-POEMS - Listening to the voices of women with a traumatic birth experience.
}

\author{
Yvonne Fontein-Kuipers, Diana Koster*, Chantal Romijn, Elvira Sakko, Catelijne Stam, Nienke \\ Steenhuis, Daniëlle de Vries, Ilze van Willigen
}

Research Centre Innovations in Care and School of Midwifery Education, Rotterdam University of Applied Sciences, Rotterdam, The Netherlands

\begin{abstract}
This qualitative study, utilizing a feminist perspective, aimed to explore and articulate women's recall of emotional birth trauma experiences. The reason being that one in every five women has a negative recall of childbirth and one in every nine women has experienced birth as a traumatic event, with sometimes detrimental implications for women and their families. Thirty-six individual narrative interviews with Dutch-speaking women were conducted. Consent was obtained and interviews were audiotaped and fully transcribed. Sentences with the "voice of the ' $I$ " were extracted from the transcripts and were constructed into I-poems, showing four key themes: (1) The journey - unmet hopes and expectations of women during pregnancy, birth and thereafter; (2) The ' $I$ ' in the storm women's notions of painful thoughts and memories; (3) The other - women's responses to the interaction with healthcare professionals; (4) The environment - sensory awareness of the birthing environment. The results described and showed the rawness and desolation of women's experiences reflected in their narratives of self, context and in relation to others, maternity care providers in specific. This study showed that acknowledging and listening to women's voices are of merit to inform (student) midwives and other healthcare professionals who are involved with childbearing women so that the significance of this experience can be understood.
\end{abstract}

Keywords: Traumatic birth experience, Midwifery, Narratives, I-poems.

Accepted on April 052018

\section{Introduction}

Becoming a mother is a significant life-changing event. The event of labor and birth profoundly marks the important and irreversible tipping point in transition - the transformation of being pregnant to being a mother (again) [1-4]. It is of importance that the event of labor and birth is a positive social, physical and psychological experience, creating joyful memories. However, one in every five woman has a negative recall of childbirth [5], whereas one in nine women has experienced childbirth as a traumatic event [6]. Birth trauma in this case refers to women who experienced the birth itself as a psychological trauma. Birth trauma refers to births that have taken short or long-term postpartum psychological toll from women - psychological distress as a direct consequence of their childbirth experience. Birth trauma doesn't only refer to Post Traumatic Stress Disorder (PTSD) that occurs after childbirth but it also includes those women who may not meet the clinical criteria for PTSD but who have some of the symptoms of the disorder [5-8]. Traumatic birth experiences are often caused by lack of control, fear, interventions, pain, lack of support and communication and lack of genuine or humanistic care [5,7-12]. Negative, distressing and traumatic experiences negatively affect breastfeeding rates [13], can take considerable maternal psychological toll [6,14-17], can result in an impaired mother-child bonding and interaction and to disequilibrium in family structures and in parenting [18,19]. Negative birth experiences might lead to postpartum physical symptoms such as excessive fatigue, vital exhaustion, and reduction in functional capacity, including sexual activity [20]. Traumatic birth experiences can even result in a wish to avoid or delay a subsequent pregnancy and birth or in a request for an elective cesarean section - due to fear of childbirth [11,21-25]. Unfortunately, these women often remain under the radar as these experiences are kept quiet - at the end of the day, childbirth is socially regarded as a joyous and happy occasion. Apparently, a social stigma is associated with voicing negative thoughts and emotions when it comes to childbirth and the aftermath of this event [26]. Birth - and the experiences of how we are born is therefore not just a process but a major life event for the woman, the baby, the family and by extension has implications for the whole of society.

Approximately 80 percent of women in the fertile life period in the Netherlands conceive and go through pregnancy and birth [27]. The negative short and long-term health outcomes that result from negative and traumatic birth experiences have their own consecutive effects on future life and the quality of life of mothers, their children, significant others, and society as a whole, including societal costs. It might not be of sole importance what factors cause these horrible experiences, it might be of much higher priority to simply listen to women's stories, to acknowledge and respect these instead of misinterpreting, underestimating, ignoring, trivializing or patronizing women and their individual experiences of childbirth [28]. Engaging with women's traumatic birth 
Citation: Fontein-Kuipers Y, Koster D, Romijn C, et al. I-POEMS - Listening to the voices of women with a traumatic birth experience. $J$ Psychol Cognition 2018;3(2):29-36.

experiences constitutes connected learning and understanding of women's experiences and of their impact. Then, society as a whole might withhold stigmatization of these events and the consequences; contributing to the prevention and reduction of a blame-culture of those mothers and parents and/ or their children who are the direct victims of these experiences. In order to do so, women with negative, distressing and traumatic childbirth experiences should therefore be given a voice. This will expand our understanding of these experiences and enable clarification of women's emotional trauma.

We performed this study in the Netherlands, aiming to give voice to women who recall the birth of their child as a negative, emotional distressing or traumatic event and who self-identified this as a traumatic experience. This paper focuses on traumatic birth experiences from the perspective of the women who experienced them, exploring the woman's intrapersonal emotions during and after the birth that affect her perception of the event.

\section{Method}

\section{Design}

The study utilized a feminist perspective as it dealt with women's experiences, aiming to provide explanations what women want and need, to overcome the invisibility of women in social research [29], to attend to power imbalances and aiming to respect women's voices [30].

\section{Participants}

Women who had a subjective experience of a traumatic childbirth, whereby traumatic childbirth was defined by the women herself, were eligible for the study. Women were included if they had a good proficiency of the Dutch language, were 18 years of age or older and had given birth in a Dutch birth setting more than six weeks and less than three years ago at a gestational age of $>37$ weeks. No distinction was made between primiparous or multiparous women, the type of care received (midwife-led care or obstetric-led care), the mode of birth and type or number of interventions. Pregnant women, cases of perinatal mortality, mothers of neonates who were admitted postpartum due to life threatening complications and/or severe congenital pathology, women who had experienced recent trauma or loss not related to childbirth and women with (acute) psychiatric conditions were excluded because of potential confounding the traumatic birth experience, being the topic of study.

\section{Procedure}

Participants were purposively recruited through a Facebook message explaining the purpose and content of the study. No definition or criteria of emotional birth trauma were given - as this was self-defined by the participants based on their own judgement of their individual experienced emotional trauma. In total, sixty-four women responded of which thirty-six women were included in the study. Women were excluded because they did not fit the inclusion criteria or when it was not possible to schedule an appointment due to the constrained timeslot of our study. The study sample was self-selective and therefore requirements for diversity were not needed [31]. The interviews were conducted between 12 March and 15 May 2016, at a time and place convenient to the participants. Prior to the interviews women received an information letter that articulated the right to refuse or withdraw at any time. In this study six final-year midwifery students were involved to collect the data, i.e. being the interviewers. The students were academically supervised by a post-doc researcher (YF) and mentored by a certified counselor (DK), being specialized in support and treatment of women with traumatic birth experiences. The students were trained (DK) in interview techniques, with emphasis on non-verbal reactions, empathy and neutral responses to the women's experiences. They were instructed how to conduct the interview with preventing it to become a therapeutic conversation. Prior to the interviews, the students conducted a pilot-interview, they read the counselor's book (DK) about the impact of negative, distressing or traumatic childbirth [32] and performed a literature search; helping to avoid to impose own structures and assumptions and to minimize the likelihood of observant-expectancy bias [33]. This course of action was critical in allowing the students to be effective interviewers [34].

\section{Data collection through narrative interviewing}

Face-tot-face narrative interviews were performed. The six interviewers (ES, CS, NS, DdV, IvW) operated in pairs, utilizing alternating roles. Each interview was coordinated by one researcher and one observer. The latter observed nonverbal communication and checked on completeness. The interviews were 45 to 90 minutes long. Interviews were audiotaped for which consent was obtained prior to the interview. Women were invited to revisit the birth that they had experienced as traumatic - to tell and reconstruct their personal story [35,36]. It was emphasized that there were no wrong answers and participants were encouraged to reveal anything they wanted to say about the topic addressed. Women were informed that they could refuse to answering questions and that they could withdraw from the interview at any moment without giving reason. The sensitivity of the topic suggested a nonhierarchical method, allowing women to retain an element of control during the interview [37]. Therefore, the role of the interviewer in our narrative study was to listen, abstaining from interruptions, but occasionally seeking clarification by asking 'how' and 'what' questions [38]. This was the approach we took and was a way of ensuring that participants were given the freedom and time to unfold their own stories.

\section{Analysis}

The recorded interviews were described verbatim and the transcripts were anonymized. We individually read the transcripts in order to determine the essence of the birth event. In a second reading we were particularly focused on the presentation of the 'voice of the 'I' for constructing I-poems $[39,40]$. In these, each instance of the pronoun, connected verb and other related words were extracted and placed on a separate line, thus building a skeletal version of the text which 
has the appearance of a poem. Subsequently, we discussed what was read to explore resonance, interpretation and understanding. With a shared narrative we began to construct the I-poems [40]. We worked together and highlighted each first person I-sentence within each transcript. We then cut and pasted these into a new document and lined up the phrases, like lines in a poem. A third reading of the data produced a thematic analysis of each transcript. The themes we identified were compared across all the transcripts [39-41].

\section{Rigor}

The transcripts were emailed to the participants, giving them an opportunity to change or remove any data. One participant responded, resulting in rectification of the transcript, enhancing trustworthiness of the analysis [33,42]. All used strategies were documented to enhance credibility, transferability, dependability and confirmability of the findings. To enhance the credibility of our findings, the final themes were discussed amongst the research team members, midwifery lecturers and students [43]. The writing of this paper was guided by the consolidated criteria for reporting qualitative research (COREQ) [44].

\section{Ethical considerations}

According to Dutch guidelines on research ethics, ethical approval was not required. For the study, we adhered to the ethical principles of the Central Committee on Research Involving Human Subject [45]. Written consent was obtained from all participants. The interviewers signed a declaration, explicating the voluntarily, confidential and anonymous character of the study. Out of moral and ethical considerations, we felt responsible to offer a backup system for the support of participants who might still be suffering from their traumatic experience. Therefore, participants were presented with casefinding questions at the end of the interview (unrecorded) to identify unresolved emotions or issues as a result of their traumatic experiences. Two certified counselors were available for the participants to offer professional help and support if necessary. This support was also offered to the women who were excluded but who had showed interest in participating in the study. We considered that women could have expressed interest in the study driven by a need to self-disclose or to seek help and support, recognizing this as coping mechanisms [46]. The excluded, non-participating women were followed up to validate this. We were aware that our recruiting message could have triggered thoughts or emotions, leaving women out on a limb. Therefore, these women were contacted by phone (YF, $\mathrm{DK})$, referring them to the available counselors when necessary. In this study confidentiality was ensured, each participant was given a number and only the researchers knew their identity. The data was handled exclusively by the researchers, was stored on password secured computers and was used for the sole purpose of the study.

\section{Results}

\section{Participants}

As this piece of research was not intended to produce generalizable results; only some basic and obstetric information was collected. The participants were between 20 and 41 years of age. All but one woman had a partner. Half of the sample had one child, whereas the other half had two to five children. A few women had received psychological support at some point in their lives before they had become pregnant. The births identified as traumatic had happened between three months to three years before the time of the interview and included births of a first child as well as of a subsequent child. Half of our sample had an induction of labor. Several participants had given birth again after the traumatic birth experience of which a few women had chosen to have an unassisted birth, i.e., a free birth. Several women had received counseling or therapy as result of the birth experience.

\section{I-poems}

The women's narratives contain details of events that appear pivotal to the participants' childbirth experiences and defined their stories. It is clear from the way the women related these events that they had a significant impact on them at the time and even for some period thereafter. We extracted four major events constructing our themes: (1) The journey; (2) The 'I' in the storm; (3) The other; (4) The environment. The themes will be illustrated by direct quotations of the I-poems.

\section{Theme 1. The journey}

This theme reflects women's responses to pregnancy, labor, the postpartum period, to received care and to early parenthood. It also reflects women's expectations and their plans during these phases and elements of the childbearing journey. All women expressed that things had turned out in a different way than they had planned, anticipated or wanted for themselves; feeling unprepared and overwhelmed by what happened, with a sense of unexpectedness and being left with the feelings on unmet needs. There was a mismatch between women's hopes and expectations and the actual experiences.

...I wanted to give birth at home

I had a birth plan

I wanted a natural birth

I was not scared, only a bit apprehensive maybe

[intrapartum referral]

I don't want to go to the hospital

I am thrown in at the deep end

I never imagined this to happen...

(32 years old, birth of 1st baby 1 year ago, augmentation because of prolonged labor- antenatal account)

...I get something for the pain 
Citation: Fontein-Kuipers Y, Koster D, Romijn C, et al. I-POEMS - Listening to the voices of women with a traumatic birth experience. $J$ Psychol Cognition 2018;3(2):29-36.

I get a drip

I am lying on my back

I don't want this

It doesn't turn out like I thought it would

I did not plan this

If only I would have known...

(30 years old, birth of $2^{\text {nd }}$ baby 6 months ago, induction of labor because of raised blood pressure - birth account)

...I have nightmares

I am supposed to be happy

I should enjoy motherhood

I can't make the memory go away

I am a failure (...) an unfit mother

I don't want this [birth] to ever, ever happen again

I have developed this fear for becoming pregnant again

I want it to be different (...) next time...

(26 years old, birth of 1 st baby 2 years ago, ventouse extraction - postpartum account)

\section{Theme 2. The 'I' in the storm}

This theme highlights the subjective nature of childbirth and shows how women's responses to the event of childbirth. All our participants voiced painful thoughts and memories, echoing devastation. All the women reported negative emotions; primarily of anger, feeling scared, being frightened, upset, panic and mental defeat.

...I can't do this

I just can't

I don't know what to do

I don't know what is happening

I feel lonely

I cry

I feel disappointed

I have no choice

I am scared

I am tired

I am angry

I scream

I can't think

I feel so stupid

I lose control

I give up
I have to survive

I feel so hopeless

I am frightened

I feel unsafe...

(32 years old, birth of 1 st baby 3 years ago, epidural)

...I keep feeling that anger

I feel constant sadness

I feel guilty

I blame myself...

(38 years old, birth of 2 nd baby 3 months ago - postpartum account)

\section{Theme 3. The other}

This theme reflects women's responses to the interaction or lack of interaction with healthcare professionals present at the birth. Women experienced many disempowering interactions with healthcare staff which left them feeling vulnerable. They wanted to be treated as individual human beings and they wanted to be listened to. Some women reported intimate aspects of care as lacking integrity. Overall, women felt that dignity and respect were lacking. They sometimes felt ignored and dismissed, dehumanized, undermined and excluded in interactions with the healthcare professionals. Some of the participants portrayed healthcare staff as uncaring and some of the women felt pressured to follow the professional.

...I am a human being

Do you hear what I am saying?

Do you take me seriously?

I am here!

What are you doing to me?

I want you to listen to me

I need an explanation

[gives up]

I do what you want me to do

I am not a wimp

I feel raped...

(31 years old, birth of 1 st baby 2 years ago, induction of labor because of raised blood pressure)

...I let them carry on (...) whatever (...) another internal examination

I have no choice

I need help

I want her [midwife] to listen to me

I want to be cared for

I am left to my own devices 
I want her [midwife] to take an interest in me

I don't trust her [midwife]

I am being overruled...

(23 years old, birth of 1 st baby 1 year ago)

...I have a name

I am being patronized

I feel abused

I feel powerless

I have no control

I did not consent to this

I deserve some respect

I have rights

I am more than just a womb...

(25 years old, birth of 1 st baby 1 year ago, Remifentanil, epidural)

\section{Theme 4. The environment}

This theme represents the sensory awareness of women during the birth, which they related to the birthing environment and had triggered a negative recall of the birth. Women were directly aware of different sensations, which they associated with the maternity care environment in the hospital setting. An environment where women perceived and engaged with external sensory stimuli. The women related the sensory experiences during the birth to negative feelings such as lack of privacy and lack of dignity.

...I see a lot of people in the room

I have no clothes on

I see faces of people

I don't know you

I hear her [midwife] high-pitched voice

I constantly hear the baby's heartbeat

I hear someone screaming in the other room

I hear a door slamming

I am stuck to the hospital bed

I am stuck to the drip, to the CTG

I sense somebody silently entering the room

I see her [midwife] angry face

I hear noises coming from all sorts of devices

I have no privacy...

( 28 years old, birth of 1 st baby 10 months ago, induction of labor because of post term gestational age)

\section{Discussion}

This study explored the subjective experiences of Dutch women who self-identified the birth of their child as a traumatic event, in order to better understand what it is women feel and perceive during these moments. The results described and showed the rawness, intensity and desolation of women's experiences reflected in their narratives and subsequently in the I-poems and the connected themes of self, the context and of the relation to others - maternity care providers in specific. The I-poems carry the components of emotion: the subjective experience, the psychological response and the expressive response - elements that might explain the birth trauma experiences. The birth trauma-related emotions expressed by our participants, suggests that women's experiences included high levels of involuntary, negative, powerful emotions, carrying intensive meaning and high levels of negative weighting. It seems that these emotions overwhelmed the birth event and the women in our study were unable to communicate their distress or to respond adequately, as described in Theme 2. While it has been recognized that the function of negative emotions is to help individuals in addressing a problem or to positively adapt to a situation, the women in our study seemed unable to do so. As a result of strong negative emotions as well as being unable to counterbalance or compensate the negative emotions with positive ones - the traumatic experience is born. Emotions interact with cognition, playing a critical role in defining the woman's subjective experience and in women's evaluation of the birth event [47]. The women in our study obviously assigned a negative evaluation to the event of birth a negative recall is born. The ingredients of emotional trauma; the unexpected character of the event, the lack of being able to control the event and feeling completely unprepared are described in Theme 1. Theme 1 shows the actual-ought selfdiscrepancy, which is known to result in distressing and negative emotions [48], as apparent in Theme 2. Theme 3 highlights non-collaborative childbirth, which has been recognized to contribute to emotional birth trauma $[11,49]$. Although medical interventions were mentioned as part of the birthing environment (Theme 4), women merely articulated that their perception during the birth was related to bodily sensory processes (i.e. sound, sight), aligning with features of embodied cognition which claims that the body plays a constitutive role in transducing environmental inputs to a negative cognition and emotional trauma [50] - the sensory information that was perceived during the birth has been stored in the brain [51] and the negative memory arises to exist or sustain.

We believe that the earnestness with which the women spoke radiated from the I-poems, underpinning the importance of acknowledgement of these experiences. The findings of this study can serve as a powerful message for (student) midwives and other healthcare professionals involved with childbearing women or those who care for women who have emotional problems as a result of a traumatic birth experience. The Ipoems can serve as a source for education and professional development. This study has provided us with the opportunity to expose real time scenes that hopefully contribute to reconditioning and sensitization of healthcare professionals as 
Citation: Fontein-Kuipers Y, Koster D, Romijn C, et al. I-POEMS - Listening to the voices of women with a traumatic birth experience. $J$

well as bringing the woman's story to public attention [26]. The accounts of our participants strongly emphasize that the best scenario is obviously to facilitate a woman's positive birth, where she feels in control, being respected and has the best outcome possible, whatever her preferences or needs. But above all, a scenario where compassion and co-humanity should be at the heart of the care for childbearing women [52]. We appreciate that women and healthcare professionals can have different perceptions and observations of one and the same birth [53] - adding to this that it are ultimately women themselves who can give meaning to the experience of the birth and not the birth-attendants [47]. By no means, do we have the intention to point a finger towards maternity care professionals as not all findings involved healthcare staff per se. We only want to articulate and highlight women's experiences, hoping to learn from the accounts given by the participants in our study in order to allow maternity care providers to be able to connect with women's subjective experiences and responses to their intrapersonal emotions and individual situation. We might not have added to the known reasons that can cause traumatic birth events [5,7-12]. We however, believe that through the use of narrative interviewing and the construction of I-poems we have organized a 'sequence of events', so that the significance can be understood through its relation to the whole of the woman's subjective experience. One of the strengths of our study is that the focus on the participants' stories is retained. In keeping with this and the feminist approach we have chosen for the study, it is imperative that the women are visible and that their stories are heard. We believe that with our I-poems we have attempted to contribute towards essentialism of traumatic experiences of childbirth, as I-poems tend to do [39].

There is a variety in the estimated prevalence of traumatic experiences of childbirth, varying from ten to as high as $30 \%$ $[6,12,54]$. Given to the fairly high number of respondents to our study's recruitment message that were obtained in a rather short period of time, suggests the many women recognizing the experience of a traumatic birth. A high number of respondents were also found in another Dutch study about traumatic birth experiences [7]. This emphasizes the need for women to raise their voices. It was striking that none of our participants mentioned the role of their partner or birthing partner during the event of birth (Theme 3), while this is known to positively affect the birth experience [17] as well as it contributes to postpartum recall and accounts of the birth [55]. In contrast to a recent Dutch study [7], none of our participants mentioned the baby, the pain or perinatal complications as a cause or element of their traumatic experience. A few women in our study had an unassisted birth after the birth they had experienced as traumatic. Although this might not be a course of action for all women with a traumatic birth experience, we know that this response is strongly associated with ascertaining human dignity, often a result of poor experiences with maternity care, a lack of faith in, and feeling unsafe with the care provided - due to the sense of loss of autonomy and the negative and disrespectful interactions with healthcare professionals [56]. These aspects seem to resonate with the experiences of the women in our study.
A number of limitations are apparent in this study and may therefore affect the usability and transferability of its findings. Firstly, the participants were all from the Netherlands and the stories they told were shared within the context of the Dutch maternity system. Secondly, our analysis relied on women's memories of their experiences and might have caused recall bias as some women spoke of births that had occurred two or three years before. However, evidence suggests that women generally recall labor and the birth of their children accurately, even after three years [5]. Thirdly, the self-selective nature of our study might have led to sampling bias and we might have included women with strong opinions about mismanagement of the birth of their child. We assume that many silences remain and need further attention and exploration. It is very likely that there have been women we were not able to reach but whose experiences are of importance; those who have never disclosed those who may have felt they had nothing to offer to this particular study and those from other cultural backgrounds or women who have reached closure, not wanting to revisit their experience. We might have missed women who have conformed and changed their values and may therefore not have wished to take part in the study. The experiences of a traumatic birth experience may also have been too painful for some women to share for the purpose of research. Approaching the women that might be lacking from this study is something to consider for future research. Women in our study selfidentified their birth experience as traumatic. We did not distinguish between levels of severity of feeling traumatized, nor did we use diagnostic instruments to assess women's mental health and wellbeing. Although we used case-finding questions to identify women who might be suffering from their experience, we don't know if women endured posttraumatic distress disorder, clinical depression, anxiety and/ or attachment problems and whether this affected their recall. This can be advisable for future research, not only for interpretation of the findings but also to enable more tailored referral of women to supportive resources than we did in this study. In addition, it is also important to acknowledge that some women in this study experienced complications of labor that played a profound or dominating role in the overall birth experience and therefore might have confused physical trauma with emotional trauma. However, based on the narratives, we believe that women had interpreted the word trauma as subjective or emotional trauma. We were not aware of women's internal locus of control, control appraisal, if women had a history of sexual trauma or if their antenatal perceptions towards birth prior to the traumatic event had a negative or fearful character; all factors which might have predisposed their birth experience and therefore their accounts $[17,57,58]$. As we utilized a qualitative design, there was no analytical tool to adjust for these aspects. Despite our thorough preparation of the interviewers, there is no certainty that interpretation observer-bias has occurred [33]. The sense of belonging to the midwifery profession - often the same professionals that women refer to in their narratives - may have led participants and researchers respectively to be reserved in narrating or making incorrect assumptions, compounding biases. Nevertheless, we believe our analysis procedure was valid. We 
worked independently, reflectively, and collaboratively $[33,42]$.

\section{Conclusion}

Four key themes emerged from the I-poems that resulted from the analysis of transcripts from interviews conducted with Dutch women who had experienced a traumatic birth. The study contributes to the understanding of the significance and impact of these experiences by explaining women's subjective experiences, their psychological and expressive responses. Findings can be beneficial for (student) midwives and other healthcare professionals that care for childbearing women. This study allowed women with traumatic birth experiences to raise their voices in order to be heard and to be respected.

\section{Acknowledgement}

The authors wish to thank the women who participated in this study and shared their personal stories. We dedicate this paper to the memory of Diana Koster.

\section{Note}

The findings of this study have led to the production of a short animation film entitled "She will remember every detail forever", giving voice to the women in our study. This film is currently being used to inform (student) midwives, other healthcare professionals and non-professionals; those who are involved with childbearing women and/or who support women with traumatic birth experiences.

\section{References}

1. Prinds C, Hvidt NC, Mogenson O, et al. Making existential meaning in transition to motherhood - A scoping review. Midwifery. 2014;30:733-41.

2. Emmanuel E, Creedy D, St John W, et al. Maternal role development: the impact of maternal distress and social support following childbirth. Midwifery. 2011;27(2): 265-72.

3. Mercer R. Becoming a mother versus maternal role attainment. J Nurs Scholarsh. 2004;36(3):226-32.

4. Nelson AM. Transition to motherhood. JOGNN. 2003;32:465-77.

5. Rijnders $M$, Baston $H$, Schönbeck $Y$, et al. Perinatal factors related to negative or positive recall of birth experience in women 3 years postpartum in the Netherlands. Birth. 2008;35:106-17.

6. Stramrood CA, Paarlberg KM, Huis in 't Veld EMJ, et al. Posttraumatic stress following childbirth in homelike and hospital settings. J Psychosom Obstetric Gynecol. 2011;32:88-97.

7. Hollander $\mathrm{MH}$, van Hastenberg E, van Dillen J, et al. Preventing traumatic childbirth experiences: 2192 women's perceptions and views. Arch Womens Ment Health. 2017;20:515-23.
8. Reed R, Sharman R, Inglis C. Women's descriptions of childbirth trauma relating to care provider actions and interactions. BMC Pregnancy Childbirth. 2017;17:21.

9. De Schepper S, Vercauteren T, Tersago J, et al. Posttraumatic stress disorder after childbirth and the influence of maternity team care during labour and birth: A cohort study. Midwifery. 2016;32:87-92.

10. Simpson M, Catling C. Understanding psychological traumatic birth experiences: A literature review. Women Birth. 2016;29:203-7.

11. Elmir R, Schmied V, Wilkes L, et al. Women's perceptions and experiences of a traumatic birth: A meta-ethnography. J Adv Nurs. 2010;66:2142-53.

12. Olde E, Hart VO, Kleber R, et al. Posttraumatic stress following childbirth: A review. Clin Psychol Rev 2006;1-16.

13. Henderson JJ, Evans SF, Straton JAY, et al. Impact of postnatal depression on breastfeeding duration. Birth. 2003;30:175-80.

14. Garthus-Niegel S, von Soest T, Vollrath ME, et al. The impact of subjective birth experiences on post-traumatic stress symptoms: A longitudinal study. Arch Womens Ment Health. 2013;16:1-10.

15. Son van $M$, Verkerk $G$, van der Hart O, et al. Prenatal depression, mode of delivery and perinatal dissociation as predictors of postpartum post-traumatic stress: An empirical study. Clin Psychol Psychother. 2005;12:297-312.

16. Beck CT. Post-traumatic stress disorder due to childbirth: The aftermath. Nurs Res. 2004;53:216.

17. Soet JE, Brack GA, DiIorio C. Prevalence and predictors of women's experience of psychological trauma during childbirth. Birth. 2003;30:36-46.

18. Ayers S, Eagle A, Waring H. The effects of childbirthrelated post-traumatic stress disorder on women and their relationships: A qualitative study. Psychol Health Med. 2006;11:389-98.

19. Skari H, Skreden M, Malt UF, et al. Comparative levels of psychological distress, stress symptoms, depression and anxiety after childbirth - A prospective population-based study of mothers and fathers. Int J Obstet Gynaecol. 2002;109:1154-63.

20. Fisher JRW, Feekery CJ, Rowe-Murray HJ. Nature, severity and correlates of psychological distress in women admitted to a private mother-baby unit. J Paediatr Child Health. 2002;38:140-5.

21. Nieminen K, Stephansson O, Ryding EL. Women's fear of childbirth and preference for cesarean section - A crosssectional study at various stages of pregnancy in Sweden. Acta Obstetricia et Gynecologica Scandinavica. 2009;88:807-13.

22. Beck TC. Birth trauma: In the eye of the beholder. Nurs Res. 2004;53:381-90.

23. Gardner PS. Previous traumatic birth: An impetus for requested cesarean birth. J Perinat Educ. 2003;12:1.

24. Hofberg K, Ward MR. Fear of pregnancy and childbirth. Postgrad Med J. 2003;79:505-10. 
Citation: Fontein-Kuipers Y, Koster D, Romijn C, et al. I-POEMS - Listening to the voices of women with a traumatic birth experience. $J$ Psychol Cognition 2018;3(2):29-36.

25. Gottvall K, Waldenström U. Does a traumatic birth experience have an impact on future reproduction? BJOG. 2002; 109:254-60.

26. Edwards E, Timmons S. A qualitative study of stigma among women suffering postnatal illness. J Ment Health. 2009; 14:471-81.

27. Wobma E. Mannen en vrouwen in Nederland [Men and women in the Netherlands]. Den Haag: Centraal Bureau voor de Statistiek: Bevolkingstrends. 2011;37-42.

28. Henderson J, Redshaw M. Sociodemographic differences in women's experience of early labour care: A mixed methods study. BMJ Open. 2017;7(7):e016351.

29. Lee RM. Doing research on sensitive topics. London: Sage. 1993.

30. Webb C. Feminist research: definitions, methodology, methods and evaluation. J Adv Nurs. 1993;18:416-23.

31. Almark P. Should research samples reflect the diversity of the population? J Med Ethics. 2004;30:185-9.

32. Koster D. The myth of perfection in childbirth. Tielt: Lannoo nv. 2016.

33. Boeije H. Analyseren in Kwalitatief Onderzoek; Denken en Doen [Analysis in qualitative research]. Den Haag, Netherlands: Boom Lemma Uitgevers. 2014.

34. Comartin E, Gonzàlez-Prendes A. Dissonance between personal and professional values: Resolution of an ethical dilemma. J Soc Work Values Ethics. 2011;8.

35. Anderson $\mathrm{C}$, Kirkpatrick $\mathrm{S}$. Narrative interviewing. Int J Clin Pharmacol. 2016;38:631-4.

36. Muylaert CJ, Sarubbi J, Gallo PR, et al. Narrative interviews: An important resource in qualitative research. Rev Esc Enferm USP. 2014;48:184-9.

37. Oakley A. The Ann Oakley Reader. Bristol: Policy Press. 2005.

38. Kvale S. Doing interviews. Los Angeles: Sage. 2007.

39. Edwards R, Zeller S. Shifting analytic ontology: Using Ipoems in qualitative longitudinal research. Qual Res. 2012;12:202-17.

40. Zambo R, Zambo D. Using I-Poems to hear the voices and understand the actions of EdD students conducting action research. Qual Rep. 2013;18:1-17.

41. Gilligan C, Spencer R, Weinberg MK, et al. On the listening guide: A voice-centred relational method. In: PM Camic PM, Rhodes JE, Yardley L (Eds.) Qualitative research in psychology: Expanding perspectives in methodology and design. Washington, DC: American Psychological Association Press. 2003.

42. Flick E. An introduction to qualitative research. Sage Publications, London, UK. 2014.

43. Vincent AA, Brown KM, Mangione T. Qualitative Analysis on Stage: Making the research process more public. Educ Res. 2002;31.

44. Tong A, Sainsbury P, Craig J. Consolidated criteria for reporting qualitative research (COREQ): A 32-item checklist for interviews and focus groups. Int $\mathrm{J}$ Qual Health Care. 2007;19:349-57.
45. http://www.ccmo.nl/en/your-researchdoes-it-fall-underthe-wmo

46. Fontein-Kuipers $\mathrm{Y}$, van Limbeek E, Ausems M, et al. Using intervention mapping for systematic development of a midwife-delivered intervention for prevention and reduction of maternal distress during pregnancy. Int $\mathbf{J}$ Womens Health Wellness. 2015;1:008.

47. Mordka C. What are emotions? Structure and function of emotions. Studia Humana. 2016;5:29-44.

48. Loftus J, Namaste P. Expectant mothers: Women's infertility and the potential identity of biological motherhood. Qual Sociol Rev. 2011;7(1):36-54.

49. Thomson G, Downe S. Widening the trauma discourse: The link between childbirth and experiences of abuse. J Psychosom Obstetr Gynecol. 2008;29:268-73.

50. Varela FJ, Thompson E, Rosch E. The embodied mind (revised edition). Cambridge, Massachusetts: The MIT Press. 2016.

51. Engel KE, Singer W. Temporal binding and the neural correlates of sensory awareness. Trends Cogn Sci. 2001;5:16-25.

52. Berg M. A midwifery model of care for childbearing women at high risk: Genuine caring in caring for the genuine. J Perinat Educ. 2005;14(1):9-21.

53. Borelli SE. What is a good midwife? Insights from the literature. Midwifery. 2014;30:3-10

54. Ayers S. Delivery as a traumatic event: Prevalence, risk factors and treatment for postnatal posttraumatic stress disorder. Clin Obstetr Gynecol. 2004;47.

55. Iles J, Slade P, Spiby H. Posttraumatic stress symptoms and postpartum depression in couples after childbirth: The role of partner support and attachment. J Anxiety Disord. 2011;25:520-30.

56. Feely C, Thomson G. Why do some women choose to free birth in the UK? An interpretative phenomenological study. BMC Pregnancy Childbirth. 2016;16.

57. Ayers S, Pickering AD. Women's expectations and experience of birth. Psychol Health. 2005;20:79-92.

58. Lowe NK. Self-efficacy for labor and childbirth fears in nulliparous pregnant women. J Psychosom Obstetr Gynecol. 2000;21.

\section{*Correspondence to:}

Yvonne Fontein-Kuipers

Rotterdam University of Applied Sciences

Institute for Healthcare

Research Centre Innovations in Care and School of Midwifery Education

Rochussenstraat 198

3015 EK Rotterdam

Netherlands

Tel: + $31(0) 107946166$

E-mail: j.a.c.a.fontein-kuipers@hr.nl 